Supporting Information for:

\title{
Highly Mesoporous Ru-MIL-125-NH2 Produced by Supercritical Fluid for Efficient Photocatalytic Hydrogen Production
}

Fanyu Zhang, ${ }^{1,2}$ Bingxing Zhang, ${ }^{1,2}$ Jiaqi Feng, ${ }^{2,3}$ Xiuniang Tan, ${ }^{1,2}$ Lei Liu, ${ }^{* 2,3}$ Lifei Liu, ${ }^{1,2}$ Buxing Han, ${ }^{1,2}$ Lirong Zheng, ${ }^{4}$ Jing Zhang, ${ }^{4}$ Jing Tai ${ }^{1}$ and Jianling Zhang $* 1,2$

${ }^{1}$ Beijing National Laboratory for Molecular Sciences, CAS Key Laboratory of Colloid, Interface and Thermodynamics, Institute of Chemistry, Chinese Academy of Sciences, Beijing, 100190, P.R.China.

${ }^{2}$ University of Chinese Academy of Sciences, Beijing, 100049, P.R.China.

${ }^{3}$ Institute of process engineering, Chinese Academy of Sciences, Beijing, 100190, P.R.China.

${ }^{4}$ Beijng Synchrotron Radiation Facility (BSRF), Institute of High Energy Physics, Chinese Academy of Sciences, Beijing 100049, P.R.China.

E-mail: zhangjl@iccas.ac.cn; liulei@ipe.ac.cn 


\section{Supplementary Figures}

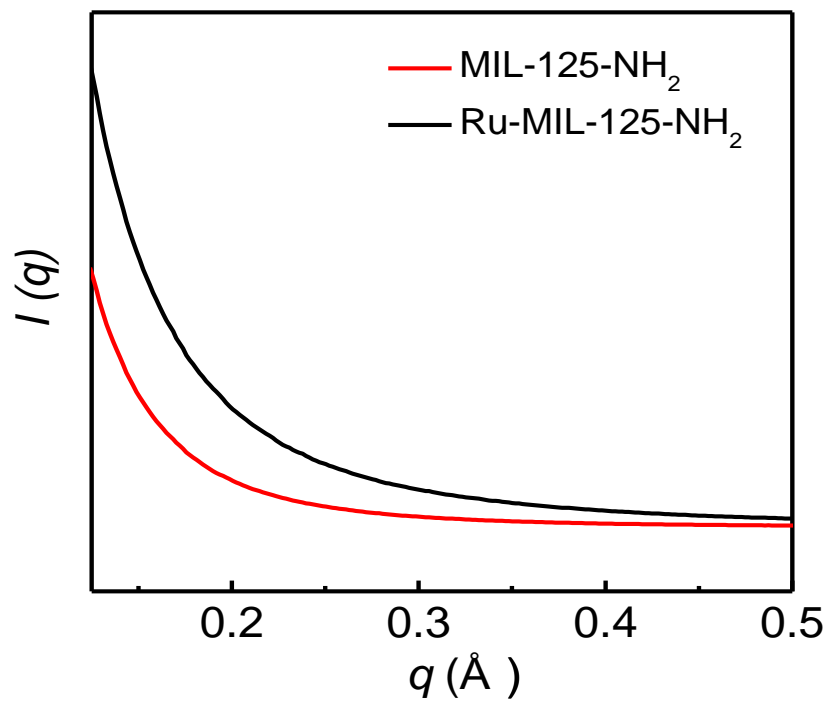

Figure S1. SAXS of MIL-125- $\mathrm{NH}_{2}$ and Ru-MIL-125- $\mathrm{NH}_{2}$.

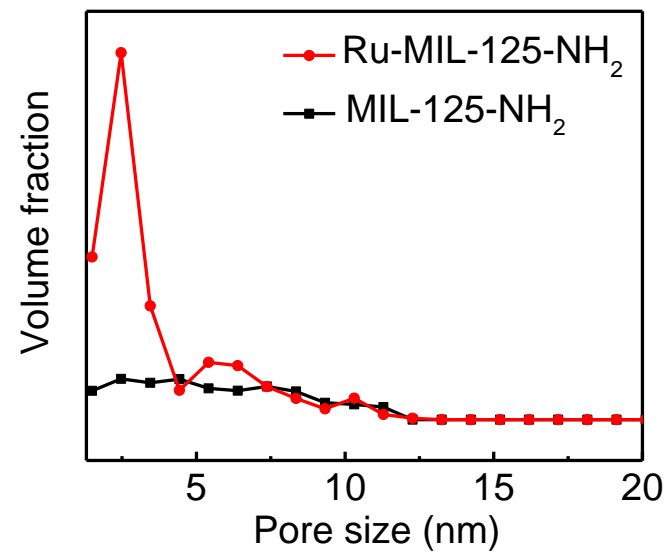

Figure S2. Histograms of the calculated radius size distributions according to Monte Carlo fits. ${ }^{1}$ The mesopore size of Ru-MIL-125- $\mathrm{NH}_{2}(\sim 4 \mathrm{~nm})$ is consistent with that determined by $\mathrm{N}_{2}$ adsorption method $(\sim 3.8 \mathrm{~nm})$. 


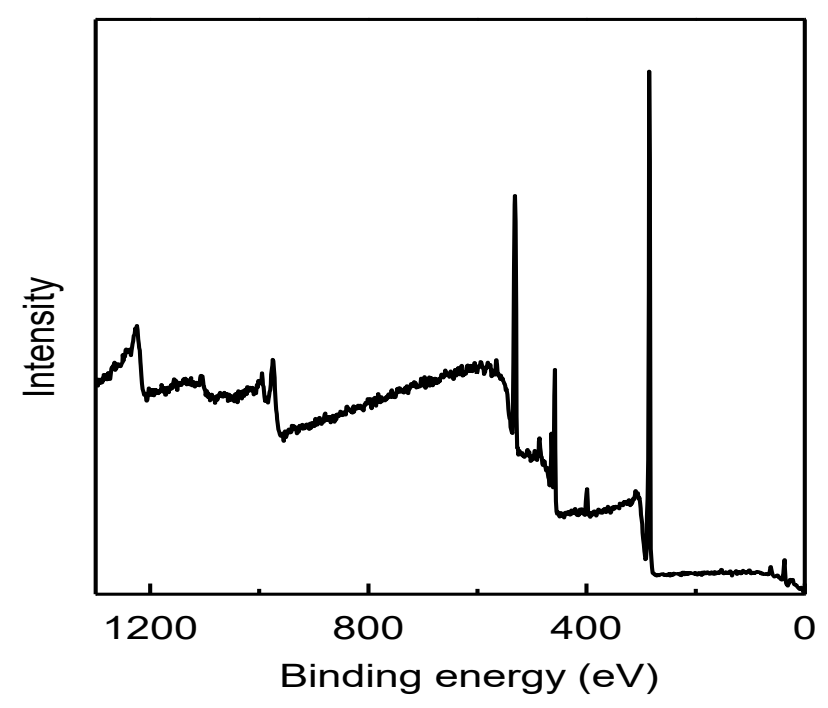

Figure S3. Wide-range XPS spectrum of Ru-MIL-125-NH 2 .

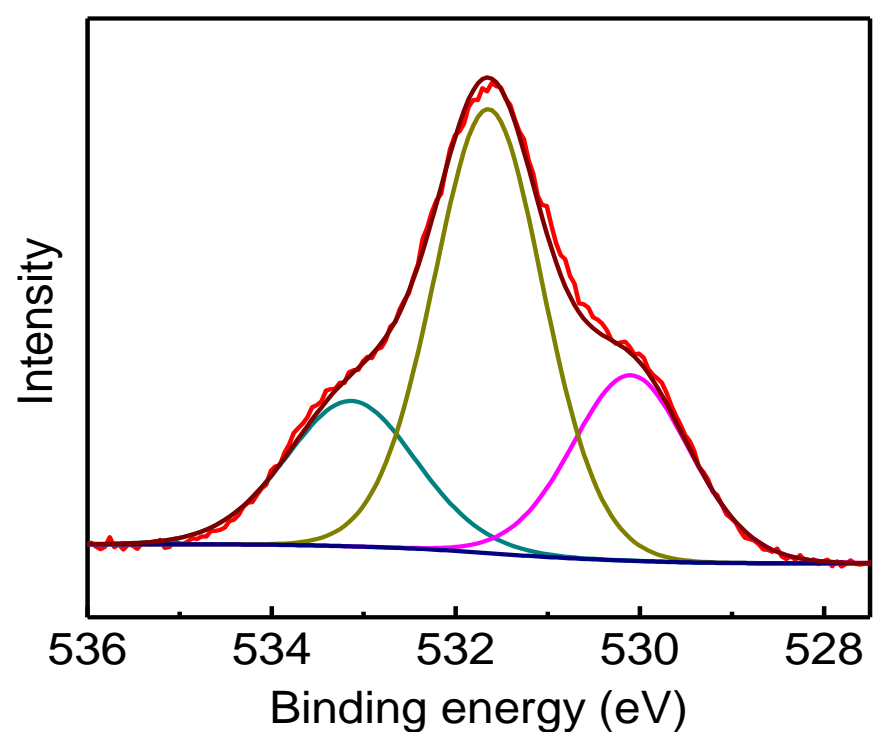

Figure S4. O 1s XPS spectrum of pristine MIL-125-NH2. 


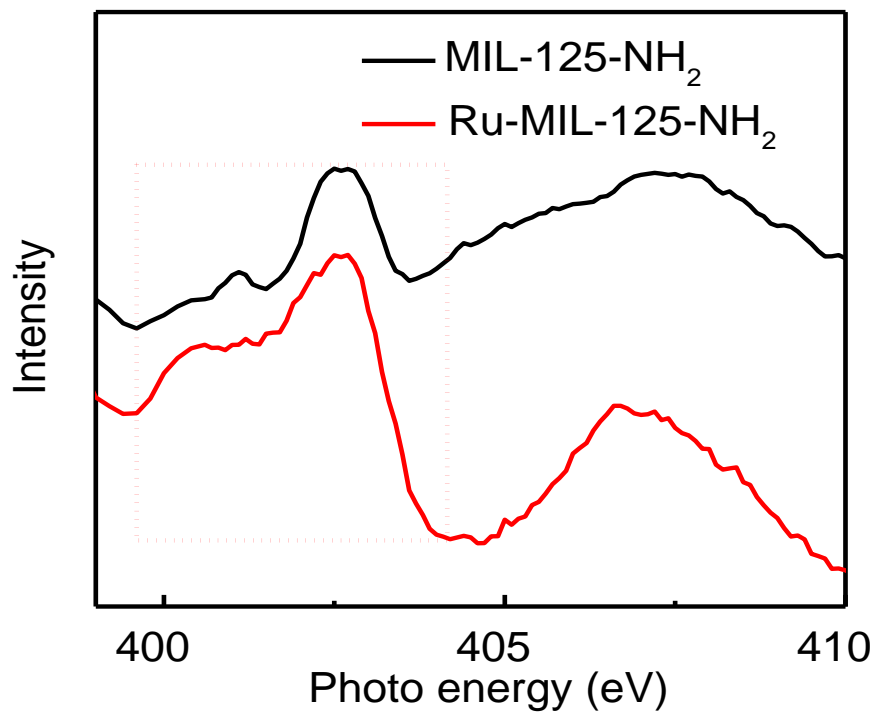

Figure S5. N K-edge soft XANES spectra of MIL-125-NH $\mathrm{N}_{2}$ and Ru-MIL-125-NH2. In comparison with MIL-125- $\mathrm{NH}_{2}$, the $\mathrm{N}$ K-edge soft XANES spectrum of $\mathrm{Ru}-\mathrm{MIL}-125-\mathrm{NH}_{2}$ is broadened (as marked in red rectangle), indicating the existence of coordinated $\mathrm{N}$ with $\mathrm{Ru}^{2}$

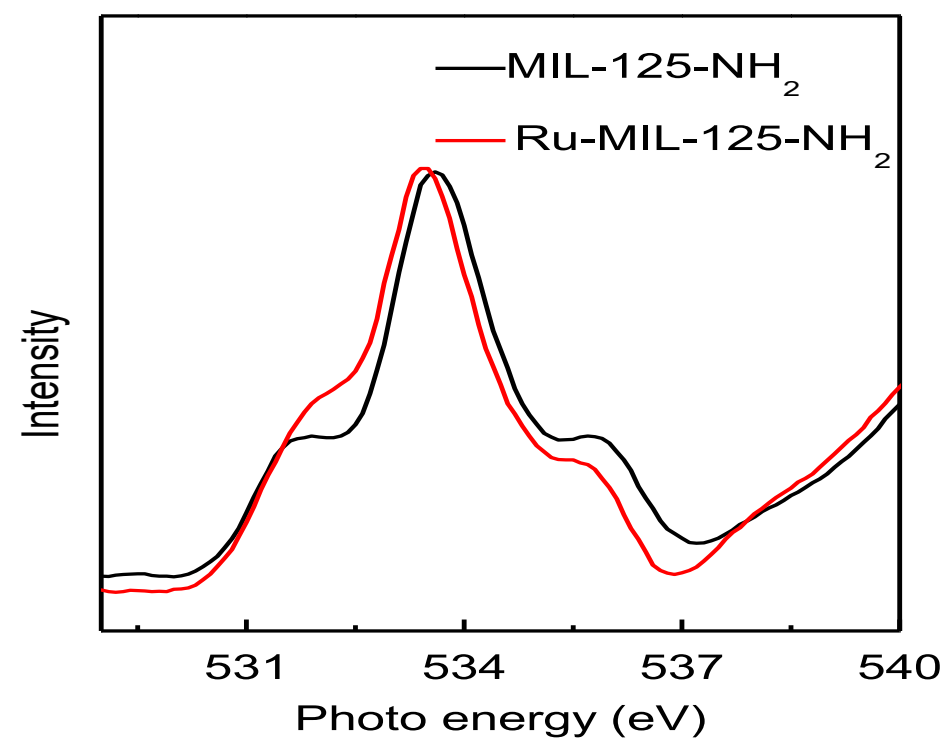

Figure S6. O K-edge soft XANES spectra of MIL-125-NH2 and Ru-MIL-125-NH2. The peak in $\mathrm{O}$ K-edge soft XANES spectrum of the Ru-MIL-125- $\mathrm{NH}_{2}$ moves to lower energy compared with MIL-125- $\mathrm{NH}_{2}$, caused by the existence of coordinated $\mathrm{O}$ with $\mathrm{Ru}$ and the distortions of the coordination environment of $\mathrm{Ti}$ which will be discussed in following. , $^{3,4}$ 


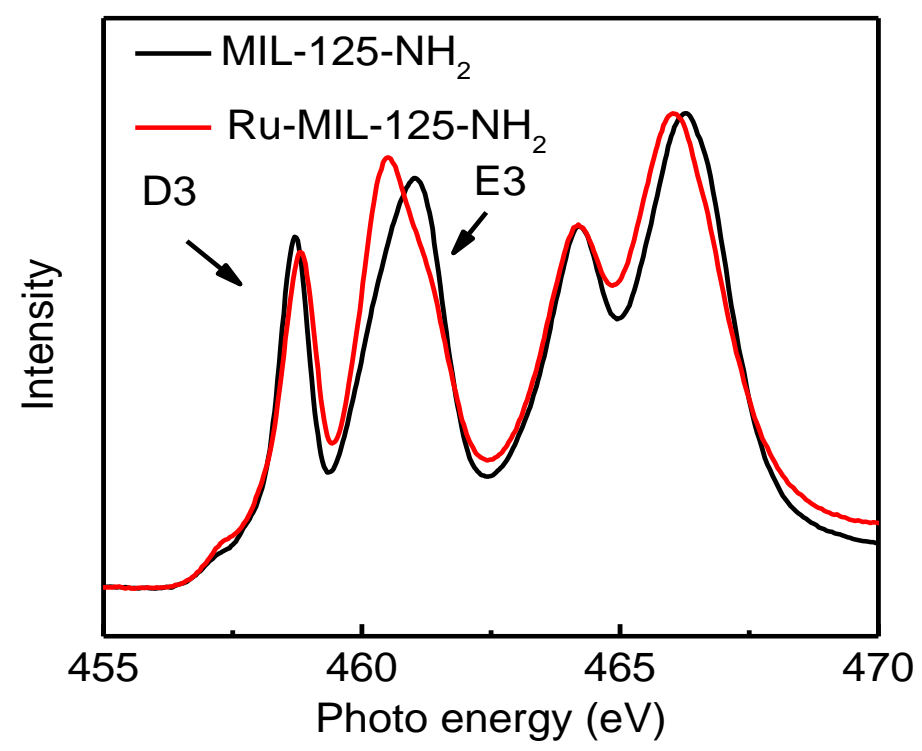

Figure S7. Ti $\mathrm{L}_{2,3}$ edge XANES spectra of MIL-125- $\mathrm{NH}_{2}$ and Ru-MIL-125-NH2. Due to the spin-orbit coupling of $\mathrm{Ti} 2 \mathrm{p}$ core electrons, Ti $\mathrm{L}_{2,3}$ edge XANES spectrum of MIL-125- $\mathrm{NH}_{2}$ splits into two sets of peaks between 455 and $472 \mathrm{eV}$, corresponding to the $2 p_{3 / 2}\left(\mathrm{~L}_{3}\right.$-edge) and $2 \mathrm{p}_{1 / 2}\left(\mathrm{~L}_{2}\right.$-edge) electron transitions of core levels to a $3 \mathrm{~d}$ excited state of Ti atoms. Both the $\mathrm{L}_{3}$ and $\mathrm{L}_{2}$-edge spectra further split into $\mathrm{L}_{3}-\mathrm{t}_{2 \mathrm{~g}}$, L3- $e_{g}, L_{2}-t_{2 g}$ and $L_{2}-e_{g}$ features because of the low symmetry of the ligand field. The relative intensities of the double characteristic peak centered at 459 and $461 \mathrm{eV}$ (denoted as $\mathrm{D}_{3}$ and $\mathrm{E}_{3}$, respectively), splitted from the $\mathrm{L}_{3}-\mathrm{e}_{\mathrm{g}}$ broad peak, which can confirm the different distortions of the local coordination environment of Ti. The relative intensity of the $\mathrm{D}_{3}$ and $\mathrm{E}_{3}$ of $\mathrm{Ru}-\mathrm{MIL}-125-\mathrm{NH}_{2}$ is higher than that of MIL-125- $\mathrm{NH}_{2}$, which confirms the different distortions of the local coordination environment and can be ascribed to the decomposition of ligand. ${ }^{5}$ 


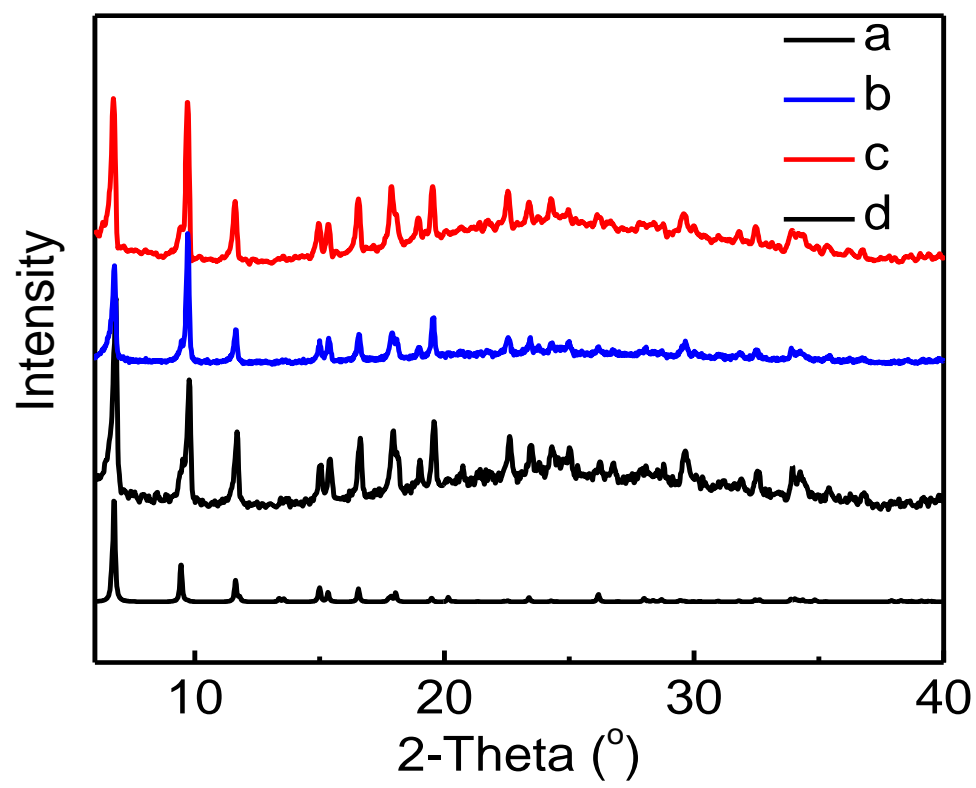

Figure S8. XRD patterns of Ru-MIL-125- $\mathrm{NH}_{2}$ synthesized at reaction time of 1 (a), 3 (b), 9 hours (c) and simulated XRD pattern of MIL-125- $\mathrm{NH}_{2}(\mathrm{~d})$.
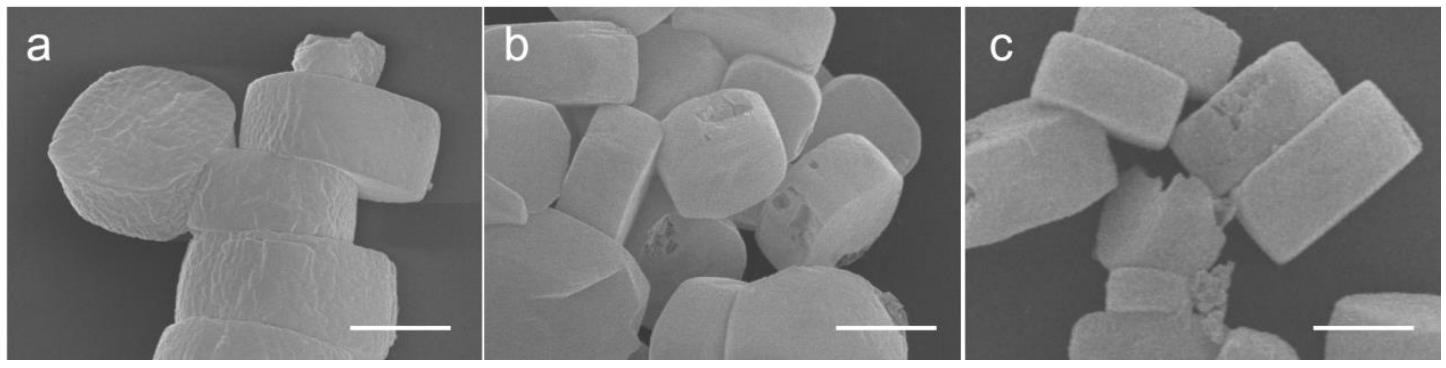

Figure S9. SEM images of Ru-MIL-125- $\mathrm{NH}_{2}$ synthesized at reaction time of 1 (a), 3 (b) and 9 hours (c). Scale bars: $1 \mu \mathrm{m}$ in a, b and c. 

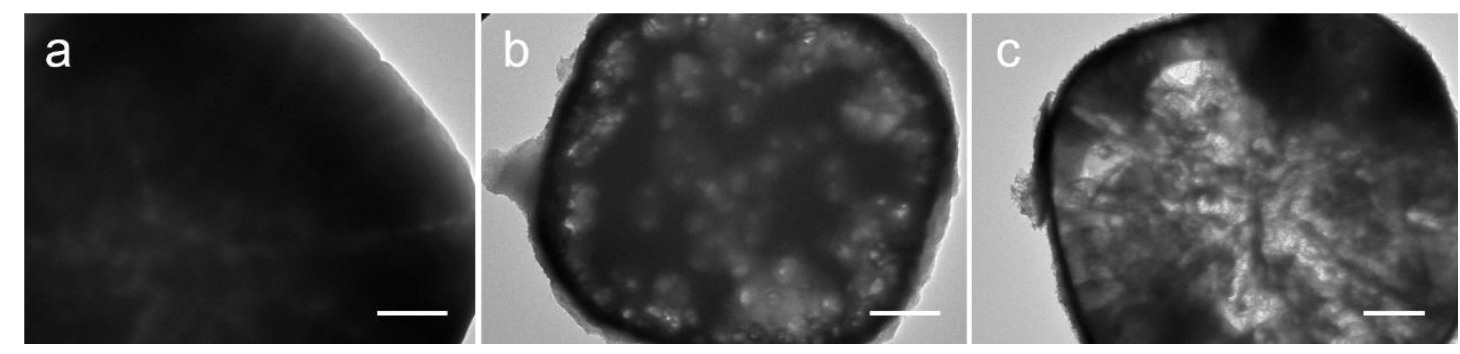

Figure S10. TEM images of Ru-MIL-125- $\mathrm{NH}_{2}$ synthesized at reaction time of 1 (a), 3 (b) and 9 hours (c). Scale bars: $200 \mathrm{~nm}$ in a, b and c.
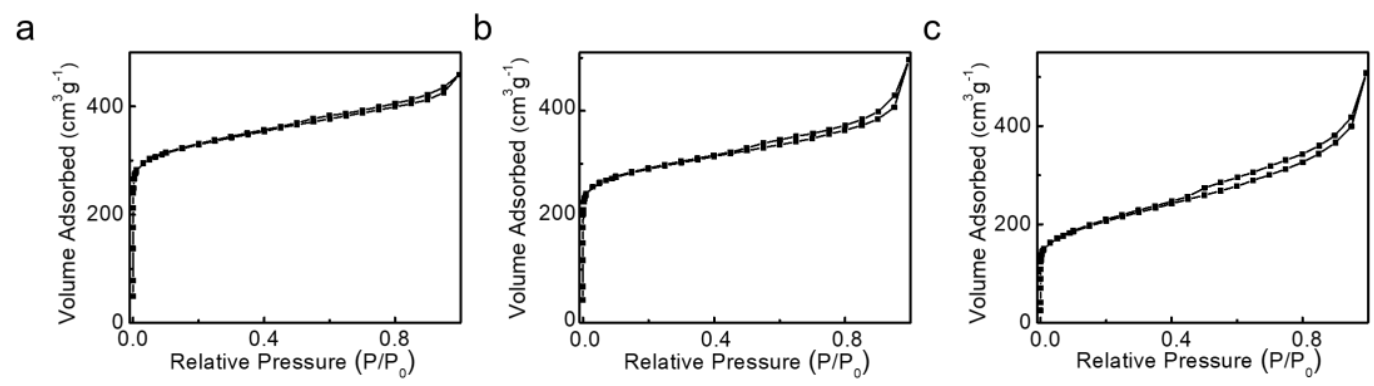

Figure S11. $\mathrm{N}_{2}$ adsorption-desorption isotherms of the Ru-MIL-125- $\mathrm{NH}_{2}$ synthesized at reaction time of 1 (a), 3 (b) and 9 hours (c). 

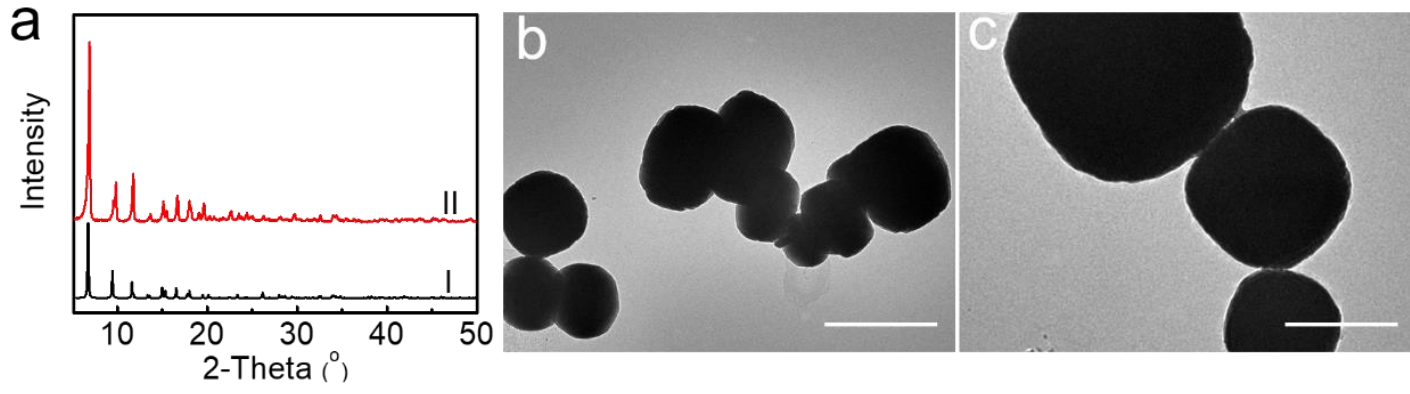

Figure S12. XRD of the post-treatment MIL-125- $\mathrm{NH}_{2}$ without $\mathrm{RuCl}_{3} \cdot \mathrm{xH}_{2} \mathrm{O}$ (I) and simulated pattern of MIL-125- $\mathrm{NH}_{2}$ (II) (a); TEM images (b and c) of the post-treatment MIL-125- $\mathrm{NH}_{2}$ without $\mathrm{RuCl}_{3} \cdot \mathrm{xH}_{2} \mathrm{O}$. Scale bars: $1 \mu \mathrm{m}$ in b, $200 \mathrm{~nm}$ in c.
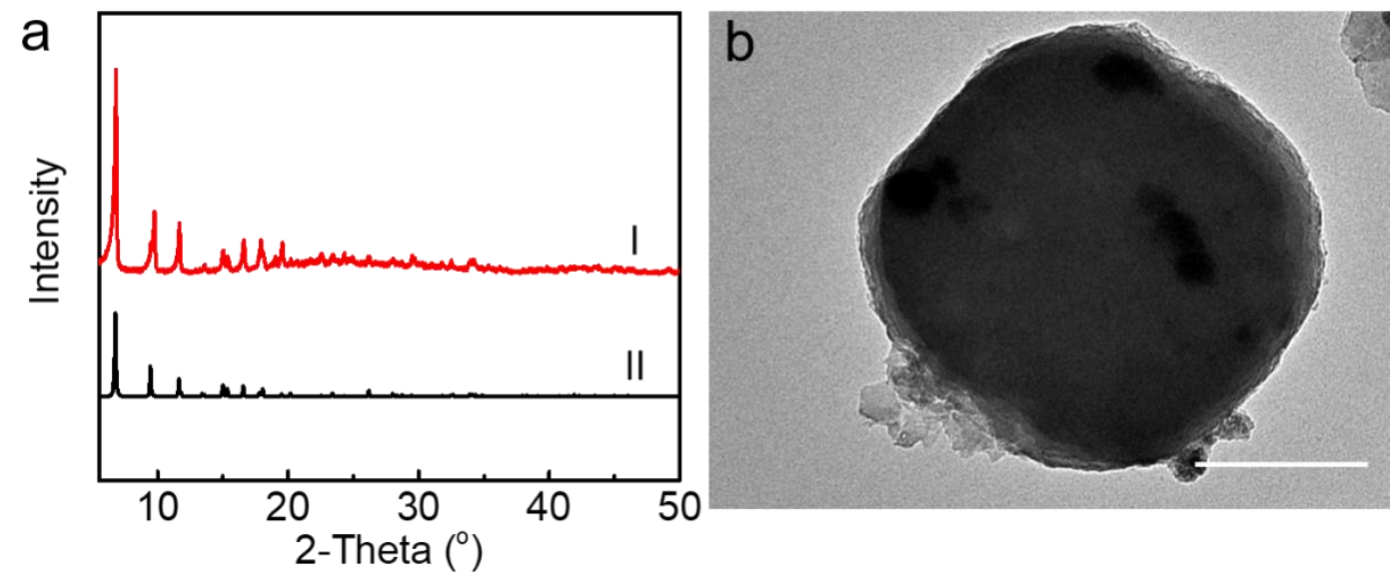

Figure S13. XRD of $\mathrm{Ru} / \mathrm{MIL}-125-\mathrm{NH}_{2}$ (I) and simulated XRD pattern of MIL-125- $\mathrm{NH}_{2}$ (II) (a); TEM image (b) of $\mathrm{Ru} / \mathrm{MIL}-125-\mathrm{NH}_{2}$ synthesized by conventional method. Scare bar: $200 \mathrm{~nm}$ in b. 

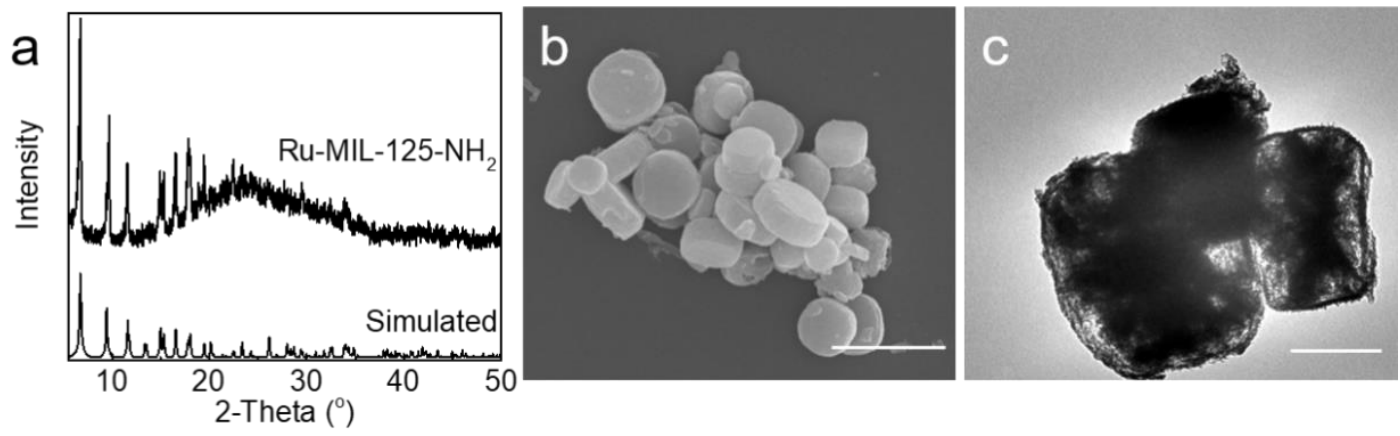

Figure S14. XRD of Ru-MIL-125- $\mathrm{NH}_{2}$ and simulated XRD of MIL-125-NH $(\mathrm{a}$ ); SEM (b) and TEM (c) images of Ru-MIL-125-NH 2 after recovering. Scale bars: $2 \mu \mathrm{m}$ in $\mathrm{b}$ and $500 \mathrm{~nm}$ in $\mathrm{c}$.

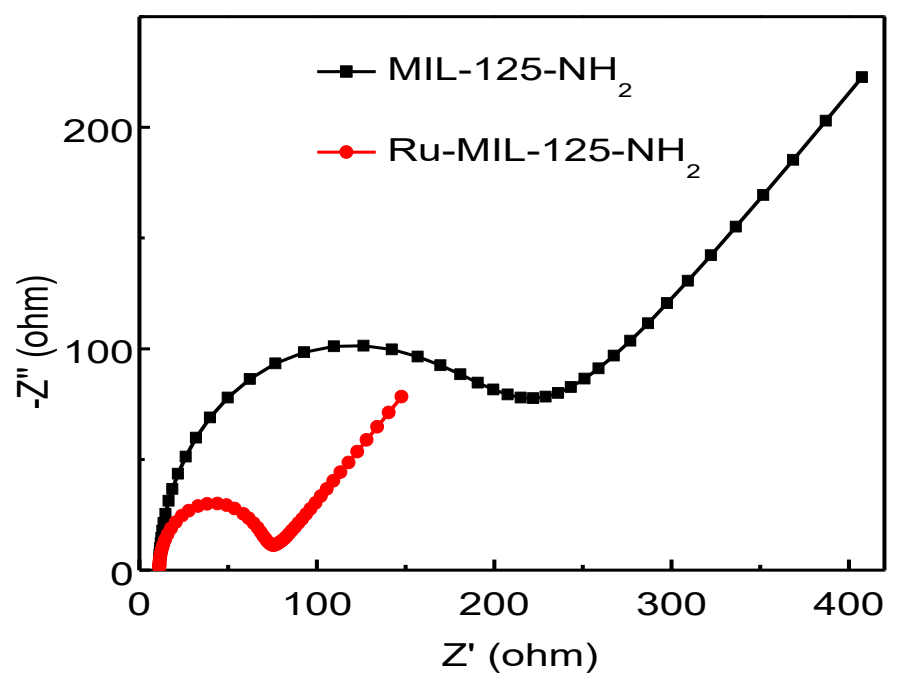

Figure S15. Electrochemical impedance spectra (EIS) Nyquist plots for the pristine MIL-125- $\mathrm{NH}_{2}$ (black) and Ru-MIL-125- $\mathrm{NH}_{2}$ (red). The EIS confirms a higher conductivity of $\mathrm{Ru}-\mathrm{MIL}-125-\mathrm{NH}_{2}$, which provides a faster electron transfer than MIL-125-NH2. It is beneficial for realizing an efficient separation of the photoinduced electron-hole pairs in the photocatalytic process. 

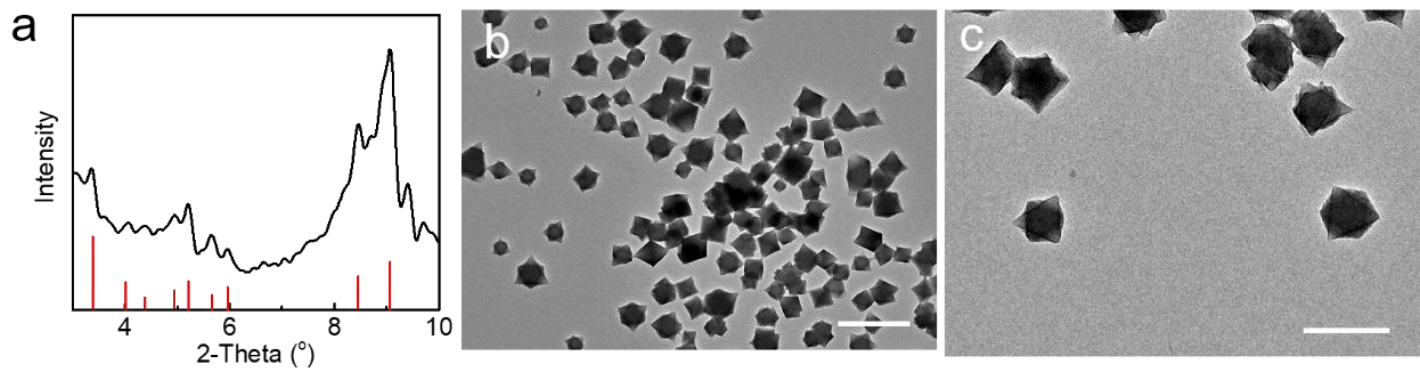

Figure S16. XRD (a) and TEM images (b, c) of the pristine MIL-101 (Fe). The vertical lines in (a) present the simulated XRD pattern of MIL-101 (Fe). Scale bars: 1 $\mu \mathrm{m}$ in $\mathrm{b}$ and $300 \mathrm{~nm}$ in $\mathrm{c}$.
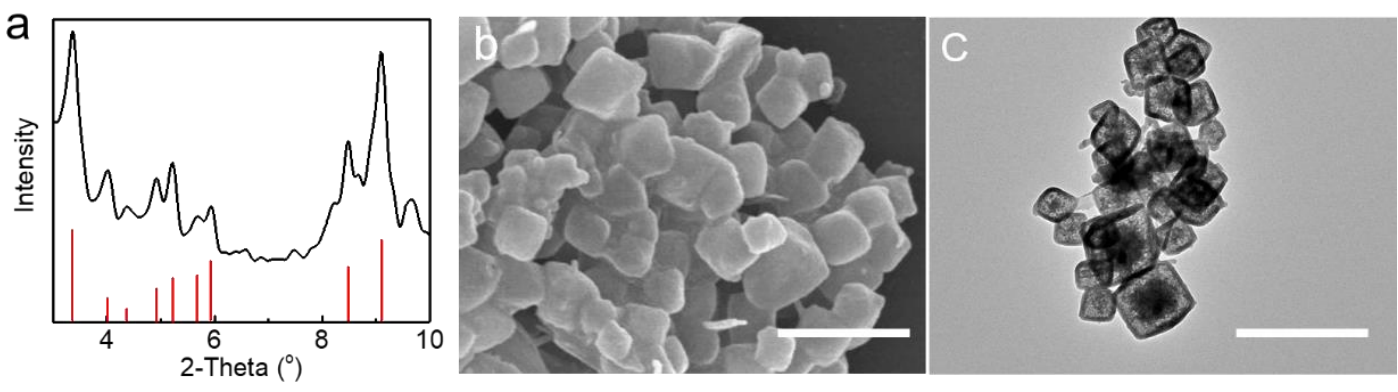

Figure S17. XRD (a) SEM and TEM images (b, c) of Ru-MIL-101 (Fe). The vertical lines in (a) present the simulated XRD pattern of MIL-101 (Fe). Scare bars: $500 \mathrm{~nm}$ in $\mathrm{b}$ and $\mathrm{c}$. 
Table S1. Contents of C, N, O, Ti and Ru determined by energy-dispersive X-ray spectroscopy.

\begin{tabular}{cccccc}
\hline Elements & $\mathrm{C}$ & $\mathrm{N}$ & $\mathrm{O}$ & $\mathrm{Ti}$ & $\mathrm{Ru}$ \\
\hline Contents & $58.91 \mathrm{wt} \%$ & $3.09 \mathrm{wt} \%$ & $14.25 \mathrm{wt} \%$ & $21.86 \mathrm{wt} \%$ & $1.89 \mathrm{wt} \%$ \\
\hline
\end{tabular}

The content of Ru determined by energy-dispersive X-ray spectroscopy is a little higher than that determined by inductively coupled plasma method (1.36 wt\%). It is because EDS is a semiquantitative analysis method and it can only give the contents of elements for the outer layers of the samples. ${ }^{6}$

Table S2. Spectral fitting parameters for Ru-MIL-125-NH 2 and MIL-125-NH2.

\begin{tabular}{cccc}
\hline Materials & $\begin{array}{c}\text { Ti-O } \\
(\% \text { Area })\end{array}$ & $\begin{array}{c}\mathrm{C}-\mathrm{O} \\
(\% \text { Area })\end{array}$ & $\begin{array}{c}\mathrm{O}-\mathrm{H} \\
(\% \text { Area })\end{array}$ \\
\hline Ru-MIL-125-NH $\mathrm{NH}_{2}$ & 39.1 & 21.4 & 39.5 \\
MIL-125-NH & 14.0 & 58.1 & 10.5 \\
\hline
\end{tabular}


Table S3. Porosity properties of Ru-MIL-125- $\mathrm{NH}_{2}$ synthesized at different time.

\begin{tabular}{cccccccc}
\hline Materials & $\begin{array}{c}\mathrm{S}_{\text {BET }} \\
\left(\mathrm{m}^{2} / \mathrm{g}\right)\end{array}$ & $\begin{array}{c}\mathrm{S}_{\text {micro }} \\
\left(\mathrm{m}^{2} / \mathrm{g}\right)\end{array}$ & $\begin{array}{c}\mathrm{S}_{\text {meso }} \\
\left(\mathrm{m}^{2} / \mathrm{g}\right)\end{array}$ & $\begin{array}{c}\mathrm{V}_{\mathrm{t}} \\
\left(\mathrm{cm}^{3} / \mathrm{g}\right)\end{array}$ & $\begin{array}{c}\mathrm{V}_{\text {micro }} \\
\left(\mathrm{cm}^{3} / \mathrm{g}\right)\end{array}$ & $\begin{array}{c}\mathrm{V}_{\text {meso }} \\
\left(\mathrm{cm}^{3} / \mathrm{g}\right)\end{array}$ & $\mathrm{V}_{\text {meso }} / \mathrm{V}_{\text {micro }}$ \\
\hline Ru-MOF-1 h & 1256.0 & 983.0 & 273.0 & 0.71 & 0.39 & 0.32 & 0.82 \\
Ru-MOF-3 h & 1096.8 & 845.9 & 250.9 & 0.76 & 0.34 & 0.42 & 1.23 \\
Ru-MOF-5 h & 996.4 & 755.8 & 240.6 & 0.70 & 0.30 & 0.40 & 1.33 \\
Ru-MOF-9 h & 735.4 & 345.1 & 390.3 & 0.79 & 0.15 & 0.64 & 4.27 \\
\hline
\end{tabular}

\section{References}

1. Bressler, I; Pauw, B. R.; Thunemann, A. F. McSAS: Software for the Retrieval of Model Parameter Distributions from Scattering Patterns. J. Appl. Crystallogr. 2015, 48, 962-969.

2. Fei, H. L.; Dong, J. C.; Wan, C. Z.; Zhao, Z. P.; Xu, X.; Lin, Z. Y.; Wang, Y. L.; Liu, H. T.; Zang, K. T.; Luo, J.; Zhao, S. L.; Hu, W.; Yan, W. S.; Shakir, I.; Huang, Y.; Duan, X. F. Microwave-Assisted Rapid Synthesis of Graphene-Supported Single Atomic Metals. Adv. Mater. 2018, 30, 1802146.

3. El Koura, Z.; Rossi, G.; Calizzi, M.; Amidani, L.; Pasquini, L.; Miotello, A.; Boscherini, F. XANES Study of Sanadium and Nitrogen Dopants in Photocatalytic $\mathrm{TiO}_{2}$ Thin Films. Phys. Chem. Chem. Phys. 2018, 20, 221-231.

4. Soriano, L.; Abbate, M.; Fernandez, A.; GonzalezElipe, A. R.; Sanz, J. M. Chemical Analysis of Ternary Ti Oxides using Soft X-ray Absorption Spectroscopy. Surf. Interface Anal. 1997, 25, 804-808.

5. Kumar, P. A.; Jeong, Y. E.; Gautam, S.; Ha, H. P.; Lee, K. J.; Chae, K. H. XANES and DRIFTS Study of Sulfated $\mathrm{Sb} / \mathrm{V} / \mathrm{Ce} / \mathrm{TiO}_{2}$ Catalysts for $\mathrm{NH}_{3}-\mathrm{SCR}$. Chem. Eng. J. 2015, 275, 142-151.

6. Rezic, I.; Spehar, M.; Jakovljevic S. Characterization of Ag and Au Nanolayers on $\mathrm{Cu}$ alloys by TLC, SEM-EDS, and ICP-OES. Mater. Corros. 2017, 55, $560-565$. 